\title{
0008-8846(95)00103-4
}

\section{MICROWAVE STUDY OF HYDRATION OF SLAG CEMENT BLENDS IN EARLY PERIOD}

\author{
X. Zhang, X.Z. Ding, T.H. Lim, C.K. Ong, and B.T.G. Tan \\ Department of Physics, National University of Singapore, Singapore 0511 \\ J. Yang \\ SsangYong Cement (Singapore) Limited, 17 Pioneer Crescent, Singapore 2262 \\ (Refereed) \\ (Received October 25, 1994; in final form January 9, 1995)
}

\begin{abstract}
Microwave technique were used to investigate the early hydration of slag cement with different slag percentages, different activators and different amount of activator. It is found that higher slag cement causes a higher dielectric constant $\varepsilon$ and a shorter induction period. But higher slag cement samples have very different electrical conductivity $\sigma$ compared with that of pure cement, their $\sigma$ curves have two extra bumps in $9-14 \mathrm{~h}$ and $22-24 \mathrm{~h}$. We found that the addition of $2 \% \mathrm{NaOH}$ and $\mathrm{Na}_{2} \mathrm{SO}_{4}$ results in large changes in $\varepsilon$ whercas the addition of $2 \% \mathrm{Ca}(\mathrm{OH})_{2}$ causes a little change in $\varepsilon$. Addition of $2 \% \mathrm{Ca}(\mathrm{OH})_{2}$ decreases the $\sigma$ but addition of $2 \% \mathrm{NaOH}$ and $\mathrm{Na}_{2} \mathrm{SO}_{4}$ increases the $\sigma$. We also found that the greater the amount of $\mathrm{Na}_{2} \mathrm{SO}_{4}$ the smaller the $\varepsilon$ but the greater the $\sigma$. The relation between the compressive strength results and the $\varepsilon$ and $\sigma$ results are also discussed.
\end{abstract}

\section{Introduction}

Blastfurnace slag is a by-product from the manufacture of pig-iron and it has cementitious properties when acted upon by a suitable alkali activator. Study of hydration of blastfurnace slag have attracted attention in recent decades. It is not only due to the potential of cost saving but also blastfurnace slag blends have some engineering advantage compared with concrete made of Portland cement only, such as lowered heat evolution, lower permeability, and greater durability in aggressive environments. The composition, reaction products, and use of blastfurnace slag, as well as the chemical, mineralogical and microstructural changes occurring in hydrated slag cement blends have been reviewed [1-6].

The principal techniques used to study slag hydration are $\mathrm{X}$-ray diffraction, electron microscopy, thermal analysis and conduction calorimetry. The first three methods are 
non-continuous methods and are not suitable for investigating the slag cement hydration in situ. Conduction calorimetry is a continuous method, and it is most widely used for the study of cement hydration in situ. However, it only relates the processes which involve changes in heat so it provides little information during the induction period of cement hydration, because the induction period only involves little heat changes.

Since the late 1970 's, there has been increased interest in using electrical methods to study cement hydration in early stage [7-23], because electrical methods are also continuous methods and can be used to study the cement hydration in situ. The principle behined cement hydration study using electrical method is that the changes in the dielectric constant and electrical conductivity of cement paste during hydration will reflect the changes of the bonding state of cement paste, and hence will relate to the change of hydration products. Thus the dielectric and electrical parameters could be used to monitor the hydration process in cement paste. Most measurements of the dielectric and electrical parameters of cement paste have been performed using a parallel plate capacitor, i.e. the cement paste is placed between two electrodes to form a capacitor. The change in capacitance of this "cement capacitor" is monitored during hydration. The dielectric constant and electrical conductivity of cement paste are then obtained from the capacitance measurement. It is reported [24] that this method could cause "electrode polarization" effect so that it causes difficulty in interpreting the conductance measurements.

Alternative is to use the microwave technique, as microwave measurement does not need electrodes and microwaves are sensitive to the water content. Some microwave works have been done to study the early hydration process of OPC and $\mathrm{C}_{3} \mathrm{~S}[8,21,25,26]$. The study of the electrical properties of slag cement is rare [17]. A microwave method developed by us has been successfully used to study the hydration of cement paste [27]. In this paper we report the results of the microwave measurement of the dielectric constant and electrical conductivity of slag cements with different slag percentages, different activators and different amount of activator during the in early hydration period.

\section{Dielectric measurements and sample preparation}

Investigations of the dielectric property of materials at microwave frequencies are typically conducted by filling a rectangular wave-guide section with a sample of the material and then determining the complex dielectric constant from measurements of the reflection and/or transmission coefficients of the dominant waveguide mode $[28,29]$. The equipment used in this work consists of a microwave vector network analyser (HP8719C) with a coax-to-waveguide adapter (HP-X281C) and a sample holder consisting of a section of the standard WR-90 waveguide. An IBM-Compatible personal computer (PC486) is set up to receive data over an IEEE-488 bus and then performs subsequent numerical analysis. A materials measurement software is used for all necessary network analyser control, calculation, and data presentation. The software controls the network analyser in the measurement of the complex reflection coefficient $S_{11}$ and $S_{22}$, and transmission coefficient $S_{12}$ and $S_{21}$ of the sample in the waveguide sample holder. It then calculates the complex dielectric constant of cement paste using these four $S$ parameters for the whole frequency range. The transmission waveguide method is used for measuring the dielectric properties of cement paste in the frequency range of $8.2-12.4 \mathrm{GHz}$. A schematic diagram of the experimental set-up is shown in Figure 1. The sample is placed into a waveguide which is connected between the two measurement planes, with one end of the sample sitting the PTFE plug. The insertion of PTFE plug is to prevent leakage of water and cement paste from sample holder as the waveguide structure 


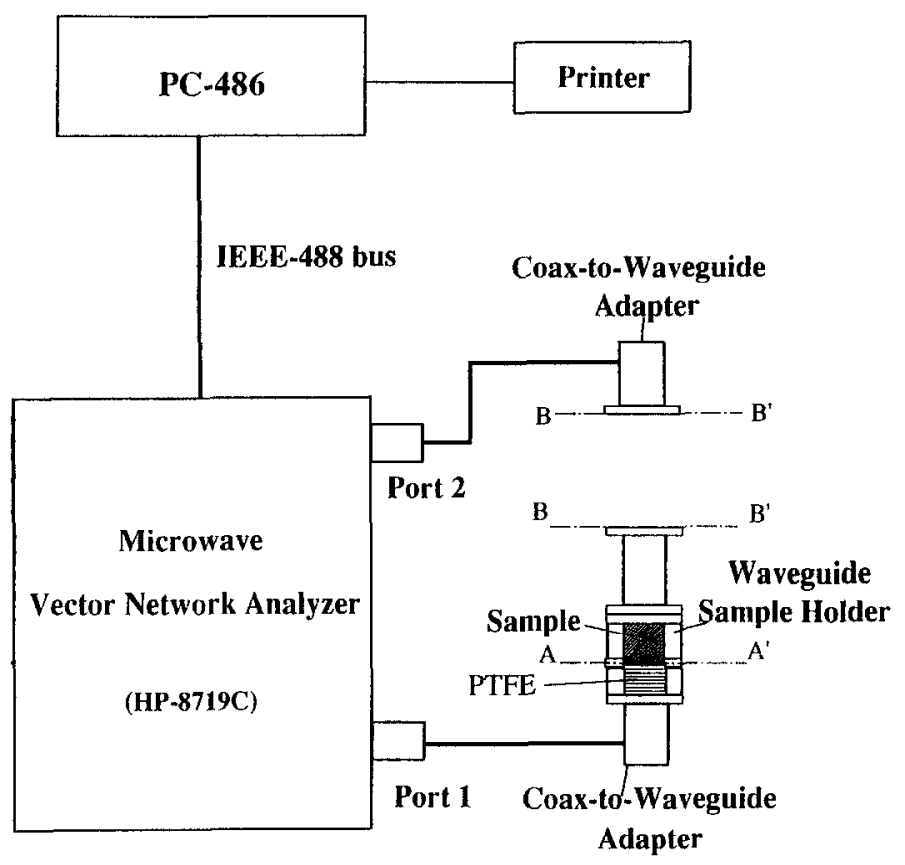

FIG 1

A schematic diagram of the experimental set-up

is set up vertically (this allows the measurement of high water-cement ratio cement paste). We calibrated the measuring system at reference planes A and B so the effect of PTFE plug is removed.

Ordinary Portland cement (OPC) and slag were used in this work. The composition of OPC and slag are given in Table 1 . The slag cement blends were prepared by mixing the required amounts of solids with de-ionized water at a water to solid ratio $(\mathrm{w} / \mathrm{s})$ of 0.4 . The slag cement blend was carefully compacted into a rectangular waveguide with a size of $22.86 \times 10.16 \times 10 \mathrm{~mm}^{3}$. The first measurement was made about 5 minutes after mixing with water. Further measurements were made at intervals of 5-10 minutes during the first 5 hours and then at intervals of $0.5-2$ hours over the next 25 hours. All measurements were made at $23 \pm 2{ }^{\circ} \mathrm{C}$.

TABLE

Component Oxides (wt \%) in OPC and Slag Cements Used

\begin{tabular}{lll}
\hline & OPC & slag \\
\hline $\mathrm{SiO}_{2}$ & 21.2 & 33.2 \\
$\mathrm{Al}_{2} \mathrm{O}_{3}$ & 5.5 & 11.6 \\
$\mathrm{Fe}_{2} \mathrm{O}_{3}$ & 3.2 & 0.4 \\
$\mathrm{CaO}$ & 63.4 & 42.8 \\
$\mathrm{MgO}$ & 1.7 & 7.0 \\
$\mathrm{SO}_{3}$ & 2.4 & 1.7 \\
$\mathrm{Na}_{2} \mathrm{O}$ & 0.13 & 0.20 \\
$\mathrm{~K}_{2} \mathrm{O}$ & 0.68 & 0.58 \\
Loss on ignition & 1.0 & 0.5 \\
\hline
\end{tabular}


In this work we also measured the compressive strength of $60 \%$ slag cement with or without activators. The slag cement was mixed with water in a Hobart mixer for three minutes before placing into the two-inch mortar cube mould. The specimens were cured in air at $25 \pm 2{ }^{\circ} \mathrm{C}(65 \%$ $\mathrm{RH}$ ). Compression test was carried out with a ELE compression machine (Digital Elect 2000) with a loading rate of $0.75 \mathrm{kN} / \mathrm{s}$.

\section{Results and discussion}

Our measurement technique can give the complex permittivity directly. Its real part $\varepsilon^{\prime}$ is the relative dielectric constant (in this paper we use the notation dielectric constant $\varepsilon$ to represent the real part of permittivity). Its imaginary part $\varepsilon$ " is related to electrical conductivity $\sigma$ via the formula $\sigma=\varepsilon_{0} \varepsilon^{\prime \prime} \omega$, where $\varepsilon_{0}$ is the dielectric constant in vacuum and $\omega$ is the angular frequency. Figure 2 shows the changes in dielectric constant $\varepsilon$ of slag cements at $9.5 \mathrm{GHz}$ with different percentage slag. For pure cement sample, dielectric constant $\varepsilon$ decreases fast in the first hour. In the period of $1-4 \mathrm{~h}$, which corresponds to the induction period, the $\varepsilon$ continues to decrease but with a slow rate of $-0.2 / \mathrm{h}$. The $\varepsilon$ starts to decrease fast at about $4 \mathrm{~h}$. In $6^{-18} \mathrm{~h}$ the $\varepsilon$ decreases $16 \%$ at fastest rate of about $-0.7 / \mathrm{h}$. The decease in $\varepsilon$ slows down at $18-19 \mathrm{~h}$.We found the $\varepsilon$ value of $30 \%$ slag cement sample is smaller than that of pure cement but the shape of the two $\varepsilon$ curves are similar. We note that the induction period of $30 \%$ slag sample is about $5 \mathrm{~h}$ which is almost $2 \mathrm{~h}$ longer than that of pure cement. We also note that in 5-20 h the drop in $\varepsilon$ of $30 \%$ slag cement is slower than that of pure cement. The $\varepsilon$ curve of $60 \%$ slag cement is very different from that of pure cement and $30 \%$ slag cement. Its initial $\varepsilon$ value is larger than that of pure cement whereas the initial $\varepsilon$ value of $30 \%$ slag sample is smaller than that of pure cement. The induction period of $60 \%$ slag sample is about 6 $\mathrm{h}$ which is longer than that of $30 \%$ slag sample. We observed a bump in $8-11 \mathrm{~h}$ after which the $\varepsilon$ drops at an almost constant rate and then its dropping rate slows down at $24 \mathrm{~h}$. It is surprising to find that the $\varepsilon$ value of $90 \%$ slag cement is larger than that of $30 \%$ slag cement but smaller than that of $60 \%$ slag cement. The induction period of $90 \%$ slag cement is the longest with a value of about 7.5-8 h. After induction period, the $\varepsilon$ does not drop but increases at about $8 \mathrm{~h}$ and starts to drop after it reaches the peak at about $9.5 \mathrm{~h}$. At about $15 \mathrm{~h}$ the $\varepsilon$ value of $90 \%$ slag sample decreases fast and then at $23 \mathrm{~h}$ it decreases at a slow rate.

Figure 3 shows the changes in electrical conductivity $\sigma$ of slag cement at $9.5 \mathrm{GHz}$ with different slag percentages. The $\sigma$ of cement changes oppositely compared with the $\varepsilon$ of cement in the first hour. The $\sigma$ increases first and then decreases after it reaches its highest value at about $1 \mathrm{~h}$. In the induction period of $1-4 \mathrm{~h}$ the $\sigma$ decreases at a slower rate. The $\sigma$ starts to decrease faster at $4 \mathrm{~h}$ and it decreases with the fastest rate in $6-18 \mathrm{~h}$. At $18-19 \mathrm{~h}$ the changes in $\sigma$ slows down. $30 \%$ slag sample has a large $\sigma$ value compared with cement, but its drop in $\sigma$ is slower than that of cement. We found a big difference between these two samples in the induction period. The $\sigma$ of cement reaches the maximum at $1 \mathrm{~h}$, whereas the $\sigma$ of $30 \%$ slag sample reaches the maximum at 2 h. The $\sigma$ curves of $60 \%$ and $90 \%$ slag samples are very different from that of $30 \%$ slag sample. The $\sigma$ of $60 \%$ slag sample decreases first then increases. It decreases again after it reaches the peak value at $3 \mathrm{~h}$. The $\sigma$ curve of $60 \%$ slag sample has the second small bump at $11 \mathrm{~h}$ and the third bump at $22 \mathrm{~h}$. The $90 \%$ slag sample has even lower starting $\sigma$ value and has a broader first bump with a peak at $5 \mathrm{~h}$. The $\sigma$ curve of $90 \%$ slag sample has a broader second bump in $9-14 \mathrm{~h}$ which is different from that of $60 \%$ slag sample, but it has a small the third bump at about $22-24 \mathrm{~h}$ which is similar to that of $60 \%$ slag sample. 


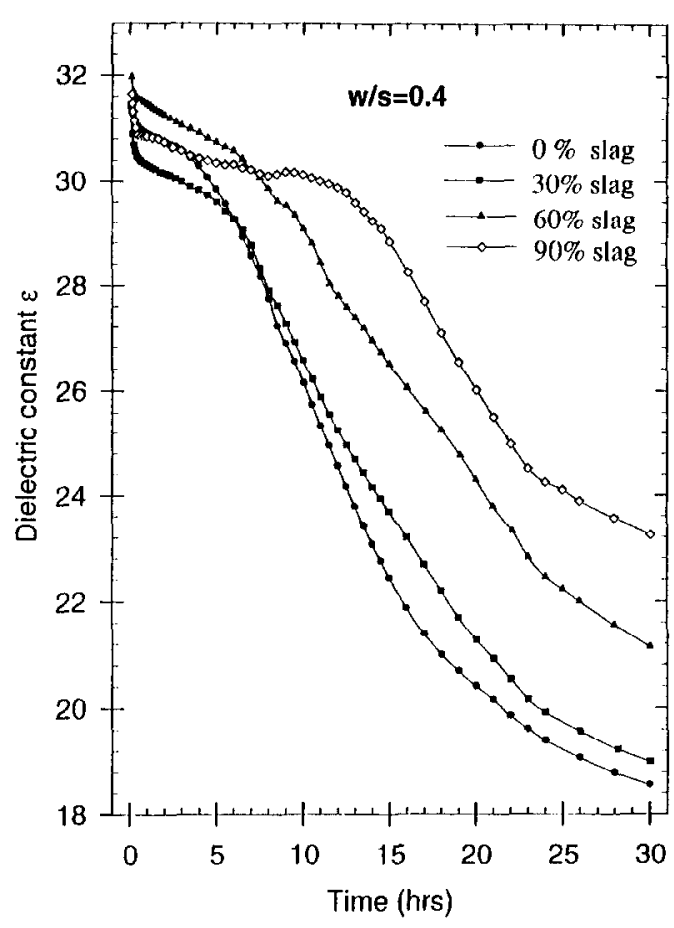

FIG 2

Changes in dielectric constant $\varepsilon$ of slag cement at $9.5 \mathrm{GHz}$ with different percentage slag

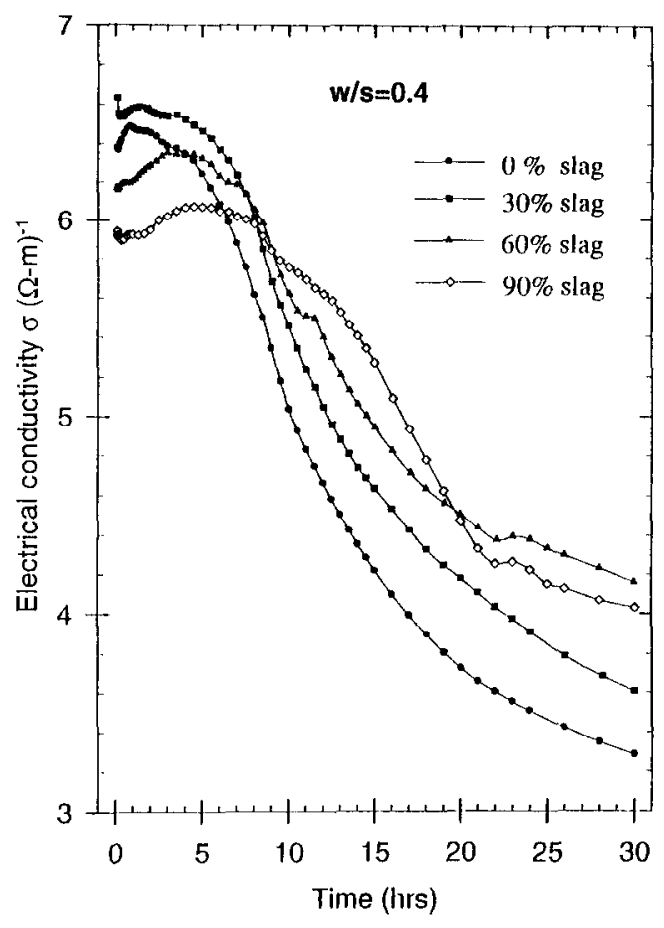

FIG 3

Changes in electrical conductivity $\sigma$ of slag cement at $9.5 \mathrm{GHz}$ with different percentage slag

Figures 4 and 5 show the effect of addition of $2 \%$ different activators on dielectric constant $\varepsilon$ of $60 \%$ slag cement in the first 24 hours and in the time range 1-28 days respectively (note that data of first $24 \mathrm{~h}$ and data of 1-28 days are measured from the different samples). Without addition of activators the $\varepsilon$ value of slag cement changes from 32 at $0 \mathrm{~h}$ to about 22 at $24 \mathrm{~h}$, after 5 days the $\varepsilon$ value drops to about 15 , then the decrease in $\varepsilon$ slows down. At 28 days the $\varepsilon$ value is about 14 . Addition of $2 \% \mathrm{Ca}(\mathrm{OH})_{2}$ causes a little changes in the shape of $\varepsilon$ curve except for the decrease in $\varepsilon$. Addition of $2 \% \mathrm{NaOH}$ and $\mathrm{Na}_{2} \mathrm{SO}_{4}$ separately cause large change in $\varepsilon$. In the first $15 \mathrm{~h}$ the effect of $\mathrm{NaOH}$ and $\mathrm{Na}_{2} \mathrm{SO}_{4}$ is almost the same, but after $15 \mathrm{~h}$ the $\varepsilon$ value of slag cement with $2 \% \mathrm{Na}_{2} \mathrm{SO}_{4}$ is smaller than that with $2 \% \mathrm{NaOH}$. We observed that addition of $2 \% \mathrm{NaOH}$ and $\mathrm{Na}_{2} \mathrm{SO}_{4}$ cause the decrease in $\varepsilon$ in $1-5$ days, and the increase in $\varepsilon$ after 5 days compared with the slag cement without activator.

Figures 6 and 7 show the effect of addition of $2 \%$ different activators on electrical conductivity $\sigma$ of $60 \%$ slag cement in the first 24 hours and in the time range 1-28 days respectively (note that data of first 24 hours and data of 1--28 days are measured from the different samples). Without addition of activator, the $\sigma$ value of $60 \%$ slag cement changes from $6.2(\Omega \mathrm{m})^{-1}$ at $5 \mathrm{~min}$. to $4.4(\Omega \mathrm{m})^{-1}$ at $24 \mathrm{~h}$, after 5 days it drops to $2.2(\Omega \mathrm{m})^{-1}$ and then the decrease in $\sigma$ slows down. At 28 days it drops to $1.8(\Omega \mathrm{m})^{-1}$. Addition of $2 \% \mathrm{Ca}(\mathrm{OH})_{2}$ decreases the value of $\sigma$ but the shape of the $\sigma$ curve is similar to that without activator. But addition of $2 \% \mathrm{NaOH}$ and $\mathrm{Na}_{2} \mathrm{SO}_{4}$ result in an increase in $\sigma$ in all the time range. The $\sigma$ value of sample with $\mathrm{NaOH}$ is higher than that 


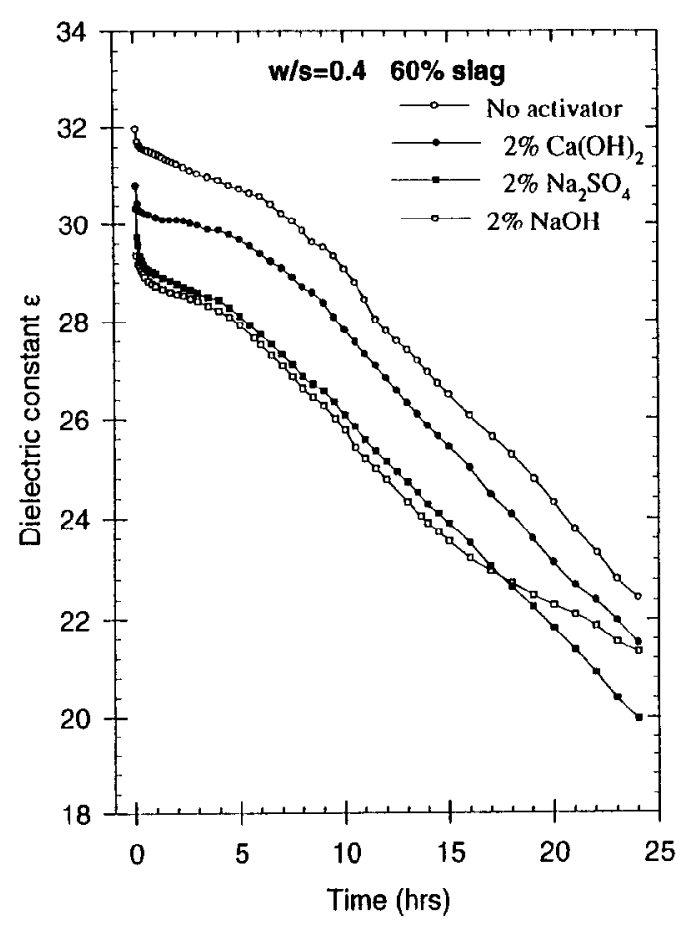

FIG 4

Effect of addition of $2 \%$ different activators on dielectric constant $\varepsilon$ of $60 \%$ slag cement in the first 24 hours

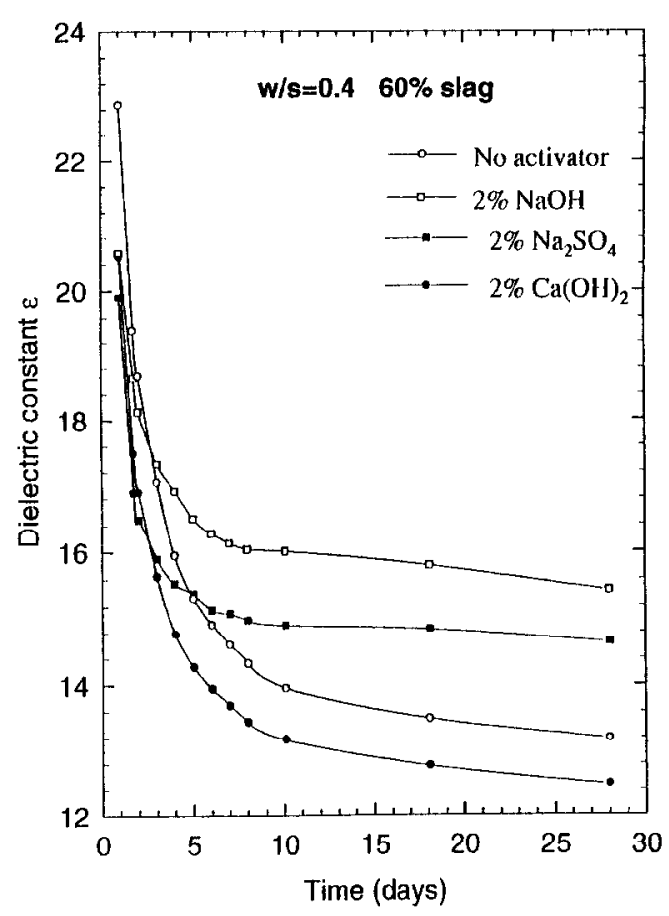

FIG 5

Effect of addition of $2 \%$ different activators on dielectric constant $\varepsilon$ of $60 \%$ slag cement in $1-28$ days

with $\mathrm{Na}_{2} \mathrm{SO}_{4}$, this may due to the sample with $\mathrm{NaOH}$ has more ions than that with $\mathrm{Na}_{2} \mathrm{SO}_{4}$. We found that addition of activator changes the $\sigma$ curves significantly in the induction period. Addition of $\mathrm{NaOH}$ and $\mathrm{Ca}(\mathrm{OH})_{2}$ causes the nearly flat $\sigma$ curve in the induction period whereas addition of $\mathrm{Na}_{2} \mathrm{SO}_{4}$ makes the bump in the induction period more obvious. It is also found that addition of $\mathrm{NaOH}$ and $\mathrm{Ca}(\mathrm{OH})_{2}$ smooth the $\sigma$ curve in the $5-15 \mathrm{~h}$.

The effect of amount of $\mathrm{Na}_{2} \mathrm{SO}_{4}$ on the $\varepsilon$ and $\sigma$ of $60 \%$ slag cement is shown in Figures 8 and 9 respectively. We observed that the more the $\mathrm{Na}_{2} \mathrm{SO}_{4}$ added the smaller the value of $\varepsilon$ but the greater the value of $\sigma$. We found that the induction period finished at 6,5 , and $4 \mathrm{~h}$ corresponding to the slag samples with 0,1 and $2 \% \mathrm{Na}_{2} \mathrm{SO}_{4}$ respectively. This result indicates that the more $\mathrm{Na}_{2} \mathrm{SO}_{4}$ added the faster is the hydration of slag cement. We also observed that addition of $\mathrm{Na}_{2} \mathrm{SO}_{4}$ smooth the $\sigma$ curve and accelerates the drop in $\sigma$ (see Figure 9).

Figure 10 shows the compressive strength of $60 \%$ slag cement with or without $2 \%$ activators. It is found that the addition of $\mathrm{Na}_{2} \mathrm{SO}_{4}$ increases the compressive strength in all ages which is in agreement with the other experiment [30]. But the addition of $\mathrm{NaOH}$ and $\mathrm{Ca}(\mathrm{OH})_{2}$ have similar effect on compressive strength. They only increase the compressive strength in early age but decrease the compressive strength at later age. It is reported that pure alkali $\mathrm{NaOH}$ did not produce the great activation of the slag [30]. The reason for that is not clear. Comparing the compressive strength result with the $\varepsilon$ and $\sigma$ results of slag cement, no correlation is found in present work.

We noted that the $\varepsilon$ curve can provide the finish time of the induction period but it provides little information on hydration process in this period. The $\sigma$ curve shows obvious change in the 


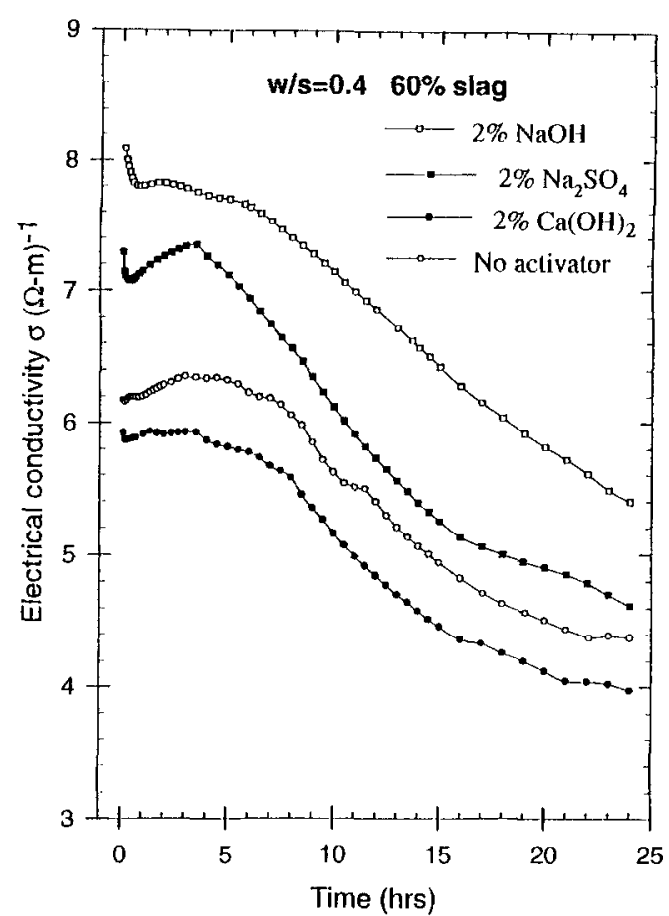

FIG 6

Effect of addition of $2 \%$ activators on electrical conductivity $\sigma$ of $60 \%$ slag cement in the first 24 hours

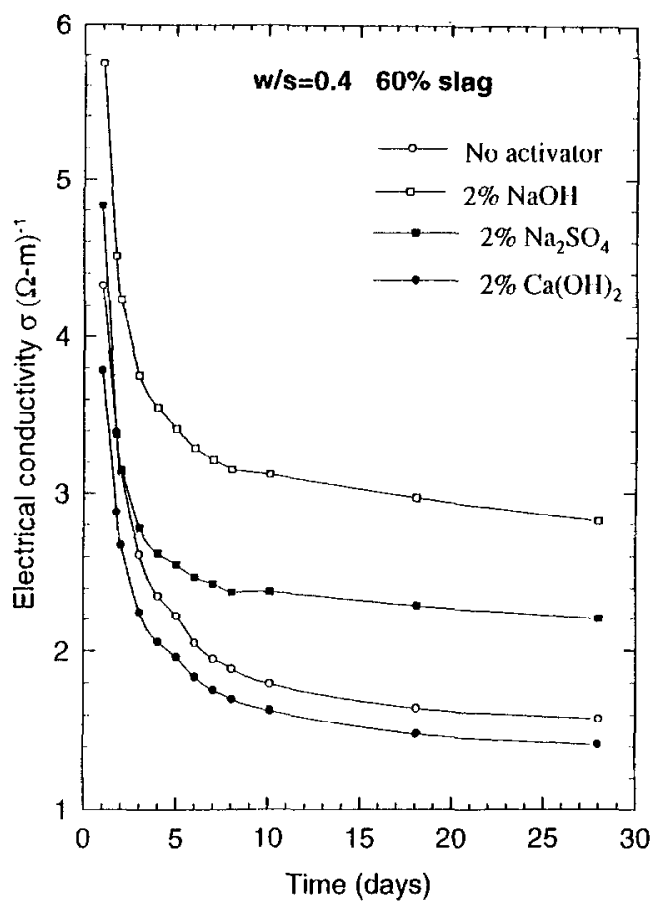

FIG 7

Effect of addition of $2 \%$ activators on electrical conductivity $\sigma$ of $60 \%$ slag cement in $1-28$ days

induction period. We noted that there are some bumps in the $\sigma$ curves especially in the high slag percentage samples. These bumps are not observed in the pure cement sample and low percentage slag cement and they may provide the information on the hydration of slag itself. The bumps disappeared when $\mathrm{NaOH}$ and $\mathrm{Na}_{2} \mathrm{SO}_{4}$ are added but remain when $\mathrm{Ca}(\mathrm{OH})_{2}$ is added. It seems that addition of $\mathrm{NaOH}$ and $\mathrm{Na}_{2} \mathrm{SO}_{4}$ changes the hydration process of slag cement much more than addition of $\mathrm{Ca}(\mathrm{OH})_{2}$. It is seen that the $\sigma$ curves of slag cement with $\mathrm{NaOH}$ and $\mathrm{Na}_{2} \mathrm{SO}_{4}$ are quite different from that of slag cement without activator but the $\sigma$ curves of slag cement with $\mathrm{Ca}(\mathrm{OH})_{2}$ is similar to that of slag cement without activator (see Figs 6 and 7). The shapes of $\sigma$ curves of slag cements with $\mathrm{NaOH}$ and $\mathrm{Na}_{2} \mathrm{SO}_{4}$ are quite different in the induction period and this difference may contribute to their different effect on the compressive strength.

\section{Conclusions}

We investigated the effect of percentage slag on the dielectric constant $\varepsilon$ and electrical conductivity $\sigma$. It is found that the higher the slag percentage, the higher the $\varepsilon$ value and the shorter the induction period. The $30 \%$ slag sample has similar $\sigma$ behaviour as that of pure cement. But 60 and $90 \%$ slag samples show very different $\sigma$ curves with two extra bumps at 9-14 h and 22-24 h. We also studied the effect of different activators on the $\varepsilon$ and $\sigma$. Addition of $2 \% \mathrm{NaOH}$ and $\mathrm{Na}_{2} \mathrm{SO}_{4}$ cause large changes in $\varepsilon$ whereas addition of $\mathrm{Ca}(\mathrm{OH})_{2}$ causes a little change in $\varepsilon$. Addition 


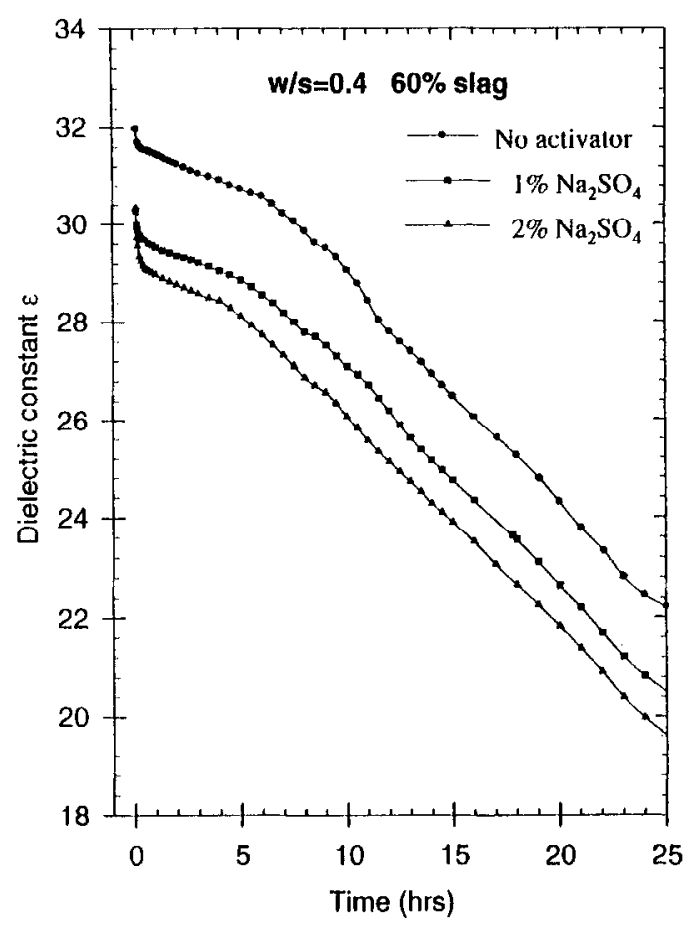

FIG 8

Effect of amount of $\mathrm{Na}_{2} \mathrm{SO}_{4}$ on dielectric constant $\varepsilon$ of $60 \%$ slag cement

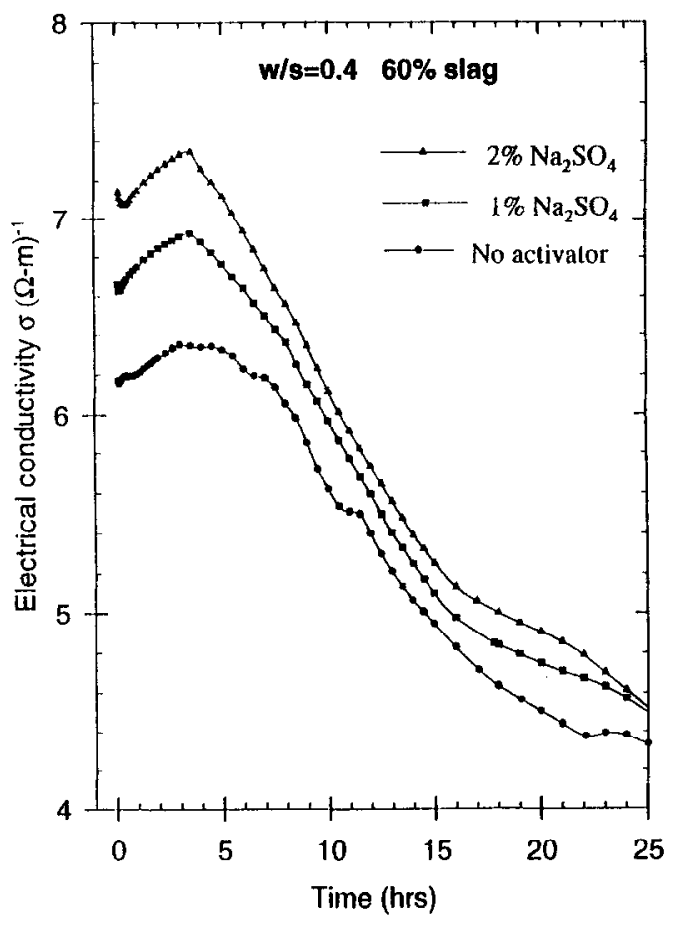

FIG 9

Effect of amount of $\mathrm{Na}_{2} \mathrm{SO}_{4}$ on electrical conductivity $\sigma$ of $60 \%$ slag cement

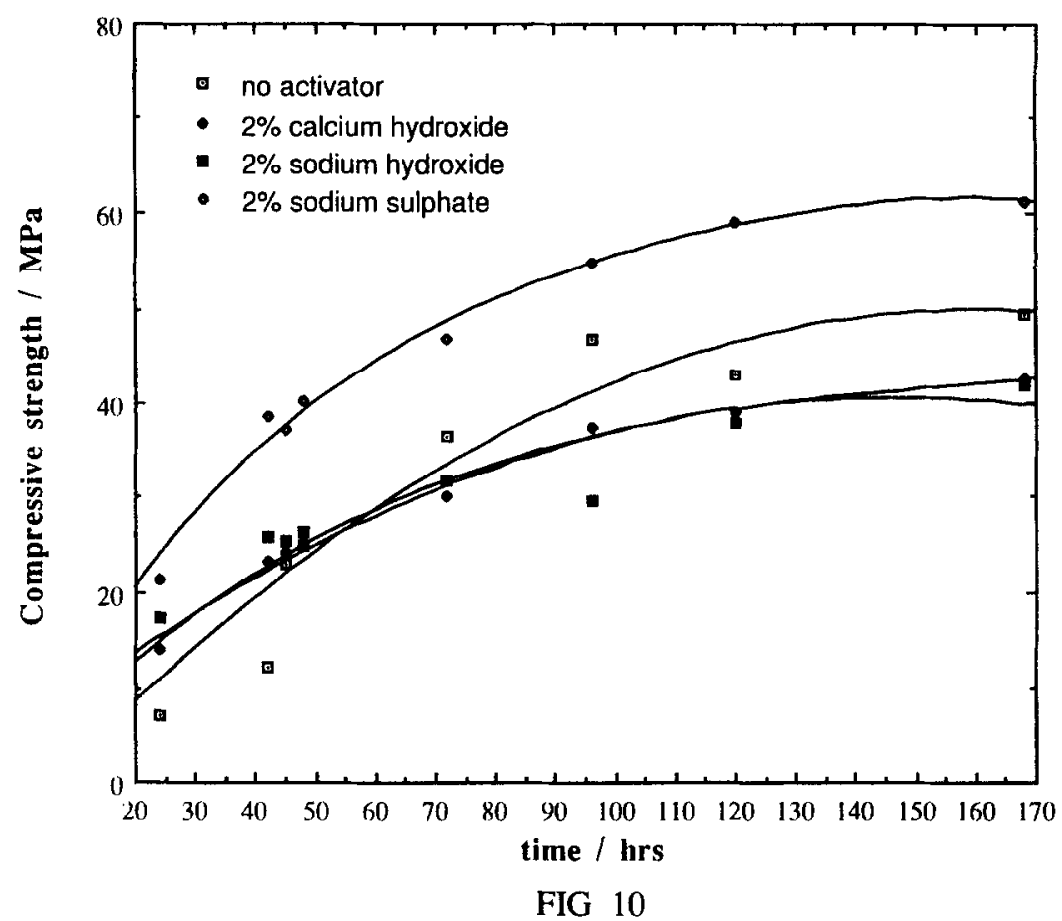

Compressive strength of $60 \%$ slag cement with or without $2 \%$ activator 
of $\mathrm{Ca}(\mathrm{OH})_{2}$ decreases the $\sigma$ but addition of $\mathrm{NaOH}$ and $\mathrm{Na}_{2} \mathrm{SO}_{4}$ increase the $\sigma$. We also found that the more the $\mathrm{Na}_{2} \mathrm{SO}_{4}$ added the smaller the value of $\varepsilon$ but the greater the value of $\sigma$.

We found that addition of $\mathrm{Na}_{2} \mathrm{SO}_{4}$ increases the compressive strength, but addition of $\mathrm{NaOH}$ and $\mathrm{Ca}(\mathrm{OH})_{2}$ cause the compressive strength to increase in early age but decrease in later age. Comparing the compressive strength results with the $\varepsilon$ and $\sigma$ results of slag cement, we found no correlation between them.

\section{References}

1. F.M. Lea, The chemistry of cement and concrete (Chemical Publishing, New York, 1973).

2. M. Regourd, in Proc. 7th Int. Congress on the Chemistry of Cements (Paris, 1980), pp. III-2, 10-26.

3. M. Daimon, in Proc. 7th Int. Congress on the Chemistry of Cements (Paris, 1980), Vol. 1, $\mathrm{pp} 2 / 1-2 / 9$.

4. H. Uchikawa, in Proc. 8th Int. Congress on the Chemistry of Cements (Rio de Janiero, 1986), Vol. 2, pp256-280.

5. F.P. Glasser, in Materials Science of Concrete II, p41-81. (1990)

6. H.F.W. Taylor, Cement Chemistry, Academic Press 1990.

7. F.D. Tamas, Cem. Concr. Res. 12, 115 (1982).

8. K. Gorur, M.K. Smit and F.H. Wittmann, Cem. Concr. Res. 12, 447 (1982).

9. W.J. McCarter and P.N. Curran, Mag. Concr. Res. 36, 42 (1984).

10. W.J. McCarter and A. B. Afshar, J. Mater. Sci. Lett. 3, 1083 (1984).

11. W.J. McCarter and A. B. Afshar, Proc. Inst. Civ. Engrs. Pt. 2, 79, 585 (1985).

12. F.D. Tamas, E. Farkas, M. Voros, and D.M. Roy, Cem. Concr. Res. 17, 340 (1987).

13. W.J. McCarter, Cem. Concr. Res. 17, 55 (1987).

14. H.C. Kim and S.S. Yoon, J. Phys. D 21, 1215 (1988).

15. W.J. McCarter and A. B. Afshar, J. Mater. Sci. 23, 488 (1988).

16. W.J. McCarter and S. Garvin, J. Phys. D. 22, 1773 (1989).

17. M. Perez-pena, D.M. Roy, and F.D. Tamas, J. Mater. Res. 4, 215 (1989).

18. M.A. Bari, J. Phys. D 23, 234 (1990).

19. J.G. Wilson, and H.W. Whittington, IEE. Proc. 137, Pt. A. 246 (1990).

20. C.A. Scuderi, T.O. Mason, and H. M. Jennings, J. Mater. Sci. 26, 349 (1991).

21. M. Moukwa, M. Brodwin, S. Christo, J. Chang, and S.P. Shah, Cem. Concr. Res. 21, 863 (1991).

22. A.M. Dunster and J. R. Parsonage, Chemistry and Industry, 304 (1992).

23. A. Berg, G.A. Niklasson, K. Brantervik, B. Hedberg and L.O. Nilsson, J. Appl. Phys. 71, 5897 (1992).

24. P.R. Camp, and S. Bilotta, J. Appl. Phys. 66, 6007 (1989).

25. J.P. Reboul, Revue de physique appliquee, Tome 13, 383 (1978).

26. F.W. Wittmann and F. Schlude, Cem Concr. Res. 5, 63 (1975).

27. X. Zhang, X.Z. Ding, C.K. Ong, and B.T.G. Tan, and J. Yang, submitted to J. Materials Science.

28. K.H. Oh, C.K. Ong and B.T.G. Tan, J. Phys. E: Sci. Instrum. 22, 876 (1989).

29. X.Z. Ding, Lu Taijing, C.K. Ong and B.T.G. Tan, J. Appl. Phys. 75(11), 7444 (1994).

30. X. Wu, W. Jiang and D.M. Roy, Cem Concr. Res. 20, 961 (1990). 